\title{
HYPERTHYROID PHASE OF HASHIMOTO'S THYROIDITIS
}

\author{
Siti Nurul Hapsari, Sidarti Soehita \\ Department of Clinical Pathology, Faculty of Medicine, Airlangga University, Dr. Soetomo Hospital, Surabaya, Indonesia. E-mail: \\ nu.neemo@gmail.com
}

\begin{abstract}
Hashimoto thyroiditis (chronic autoimmune thyroiditis) is the most common cause of hypothyroidism in iodine-sufficient areas of the world. This condition, however, can sometimes show hyperthyroidism. A 39-year-old female was admitted to hospital due to shortness of breath and tremor four hours before hospitalization. There were nausea, chest pain, cold chills, and palpitation. She was diagnosed with Hashimoto's thyroiditis and routinely received tyrosol, propranolol, and dexamethasone. Physical examination showed cervical mass, afebrile, blood pressure of $130 / 70 \mathrm{mmHg}$, pulse rate of 110 beats/minute and respiratory rate of 20 breaths/minute. Laboratory examinations showed WBC $7.53 \times 109 / \mathrm{L}, \mathrm{Hb} 11.0 \mathrm{~g} / \mathrm{dL}$ and platelet count of $168 \times 109 / \mathrm{L}$. Chest X-Ray: negative for infiltrates. Several laboratory tests were performed, abnormal results were as follows: FT4 level of $2.96 \mathrm{ng} / \mathrm{dL}$ (increased), TSH level of $0.003 \mu \mathrm{IU} / \mathrm{mL}$ (decreased), anti-TPO (antithyroid microsomal antibody) level of $306 \mathrm{IU} / \mathrm{ml}$ (increased), and IgE level of $213.6 \mathrm{IU} / \mathrm{mL}$ (increased). Peripheral blood smear, coagulation test, serum electrolytes, liver function tests, renal function tests, urinalysis, CEA and Ca 125 were within normal limits. Thyroid ultrasound was performed and showed a benign lesion. Fine needle aspiration biopsy showed lymphocytic Hashimoto's thyroiditis. Echocardiography showed hyperthyroid heart disease. Due to an increase of anti-TPO and FT4 levels, a decrease of TSH levels and lymphocytic thyroiditis from FNAB, this patient was diagnosed with a hyperthyroid phase of Hashimoto's thyroiditis. Thyroid function tests and thyroid antibody tests must be monitored to distinguish between the hyperthyroid and hypothyroid phase of Hashimoto thyroiditis.
\end{abstract}

Key words: Hashimoto thyroiditis, hyperthyroid, anti-TPO

\section{INTRODUCTION}

Hashimoto's thyroiditis (chronic autoimmune thyroiditis) is the most common cause of hypothyroidism in iodine- sufficient areas of the world. This condition, however, can sometimes show hyperthyroidism. ${ }^{1}$ It is characterized by hypothyroidism and asymmetric thyroid growth. Positive serologic test of anti-thyroid peroxidase (anti-TPO) antibody and/or anti-thyroglobulin (anti-TG) antibody supports the clinical diagnosis. The disease results in single or multiple nodules or pseudo nodules in the thyroid tissue. ${ }^{2}$

The presence of circulating thyroid antibodies, particularly anti-TPO, is the hallmark of Hashimoto's thyroiditis. However, a small number of patients are reported to have thyroid receptor blocking as well as stimulating immune globulins. In some instances, a patient may develop hyperthyroid. ${ }^{3}$ The objective of this case is to describe the hyperthyroid phase of Hashimoto's thyroiditis.

\section{CASE}

A 39-year-old female was admitted to hospital due to shortness of breath and tremor four hours before hospitalization. There were nausea, chest pain, cold chills, and palpitation, which subsided by the time she arrived at the hospital. She also had red itchy welts all over her body one day before admission. She had been diagnosed with Hashimoto's thyroiditis since seven years ago and routinely received tyrosol, propranolol, and dexamethasone.

On physical examination, the patient was afebrile, weak and alert with a GCS of $110 / 80 \mathrm{mmHg}$, a respiratory rate of 20 breaths/minute and a pulse rate of 110 beats/minute regular. As seen in Figure 1, the head and neck examination showed a cervical mass, heart examination showed a single sound of S1/S2 with no murmur, and lung examination showed vesicular sound without rhonchi and wheezing. There was urticaria all over her body.

As seen in Table 1 , on the first day, the laboratory results showed a normal number of leucocytes $(7,530 / \mu \mathrm{L})$ and a normal number of platelets $(403,000 / \mu \mathrm{L})$. There was a decreased Hemoglobin level $(11.0 \mathrm{~g} / \mathrm{dL})$, a decreased MCV (73.3 fL), a decreased $\mathrm{MCH}$ (21.6 pg), and normal MCHC $(29.5 \mathrm{~g} / \mathrm{dL})$ indicating hypochromic microcytic 


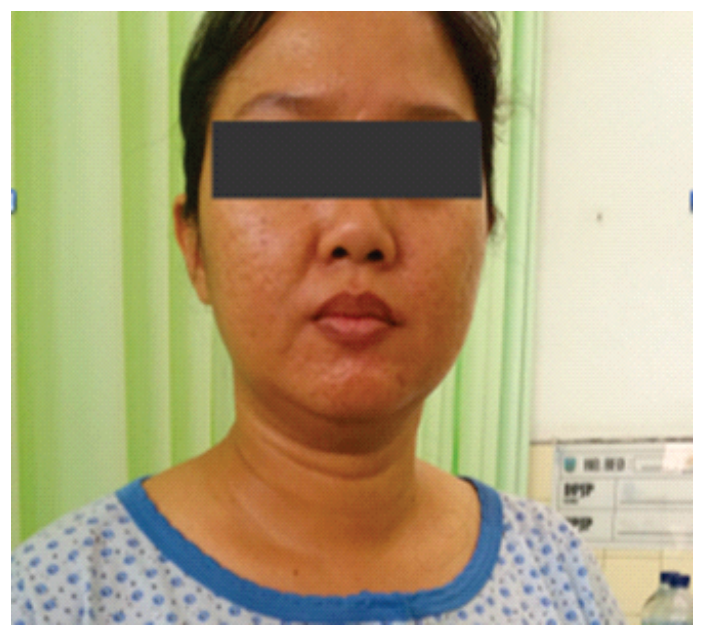

Figure 1. Patient with slight enlargement in the neck area anemia. Clinical chemistry results showed hypokalemia $(3.3 \mathrm{mmol} / \mathrm{L})$. There were no abnormalities in the coagulation studies. Thyroid panels tests showed a decrease of FT4 $(2.96 \mathrm{ng} / \mathrm{dL})$ and TSH levels $(0.003 \mathrm{uIU} / \mathrm{mL})$ indicating a state of hyperthyroidism. The patient was diagnosed with hyperthyroid and was admitted to the Department of Internal Medicine of the Dr. Soetomo Hospital. Treatment was initiated with Tyrosol 1x/day and dexamethasone injection 2x1 ampule/day.

Ultrasonography of the thyroid showed a nodule with a size of $1.2 \times 1.6 \times 4.3 \mathrm{~cm}$, with heterogenous echoparenchym and no cystic or solid lesion on the isthmus; similar to thyroiditis with a nonsuspicious lymph node. Cardiac echocardiogram showed a disturbance of diastolic function and left ventricular

Table 1. Laboratory examination on the first-day admission

\begin{tabular}{|c|c|c|c|}
\hline \multicolumn{2}{|c|}{ Hematology } & \multicolumn{2}{|c|}{ Clinical Chemistry } \\
\hline Parameters & Levels & Parameters & Levels \\
\hline $\mathrm{WBC}\left(\times 10^{3} / \mu \mathrm{L}\right)$ & 7.53 & BUN (mg/dL) & 7.0 \\
\hline$\% \mathrm{Neu}$ & 81.6 & $\mathrm{SCr}(\mathrm{mg} / \mathrm{dL})$ & 0.87 \\
\hline \% Lym & 14.3 & Alb (g/dL) & 4.25 \\
\hline \% Mono & 1.90 & $\mathrm{Na}(\mathrm{mmol} / \mathrm{L})$ & 135.0 \\
\hline$\%$ Eos & 0.60 & $\mathrm{~K}(\mathrm{mmol} / \mathrm{L})$ & 3.3 \\
\hline$\%$ Baso & 0.10 & $\mathrm{Cl}(\mathrm{mmol} / \mathrm{L})$ & 105.0 \\
\hline $\mathrm{RBC} \times 10^{6} / \mu \mathrm{L}$ & 5.10 & AST $(\mathrm{U} / \mathrm{L})$ & 21 \\
\hline $\mathrm{Hb}(\mathrm{g} / \mathrm{dL})$ & 11.0 & $\operatorname{ALT}(\mathrm{U} / \mathrm{L})$ & 11 \\
\hline Hct (\%) & 37.4 & \multicolumn{2}{|c|}{ Urinalysis } \\
\hline $\operatorname{MCV}(f L)$ & 73.3 & Parameters & Levels \\
\hline $\mathrm{MCH}(\mathrm{pg})$ & 21.6 & Glucose & Negative \\
\hline $\mathrm{MCHC}(\mathrm{g} / \mathrm{dL})$ & 29.5 & Bilirubin & Negative \\
\hline RDW (\%) & 13.1 & Keton & Negative \\
\hline Plt $\left(\times 10^{3} / \mu \mathrm{L}\right)$ & 403.000 & SG & 1.005 \\
\hline \multicolumn{2}{|c|}{ Thyroid Function Tests } & Blood & +1 \\
\hline Parameters & Levels & $\mathrm{pH}$ & 5.5 \\
\hline $\mathrm{FT}_{4}(\mathrm{ng} / \mathrm{dL})$ & 2.96 & Protein & Negative \\
\hline \multirow{2}{*}{$\mathrm{TSH}(\mathrm{uIU} / \mathrm{mL})$} & 0.003 & Urobilinogen & 0.3 \\
\hline & & Nitrite & Negative \\
\hline Coagulation Study & & Leukocyte & Negative \\
\hline Parameters & Levels & Color & Yellow \\
\hline PPT (s) & 11.0 & Clarity & Clear \\
\hline APTT (s) & 26.0 & & \\
\hline
\end{tabular}

Table 2. Current immunologic laboratory test

\begin{tabular}{cccccc}
\hline & $\mathbf{1 2 / 1 1 / 1 7}$ & $\mathbf{1 4 / 1 1 / 1 7}$ & $\mathbf{2 0 / 1 1 / 1 7}$ & $\mathbf{2 3 / 1 1 / 1 7}$ & Reference \\
\hline $\mathrm{FT}_{4}(\mathrm{ng} / \mathrm{dL})$ & 2.96 & 1.69 & 1.81 & 0.82 & $0.89-1.76$ \\
$\mathrm{TSH}(\mathrm{uIU} / \mathrm{mL})$ & 0.003 & 0.008 & 0.01 & 0.72 & $0.55-4.78$ \\
Total Ig E $(\mathrm{IU} / \mathrm{mL})$ & & 213.6 & & & $2-214$ \\
Anti TPO $(\mathrm{IU} / \mathrm{mL})$ & & & & 306 & $<35$ \\
\hline
\end{tabular}


remodeling, consistent with hyperthyroid heart disease. The patient had a history of thyroid tests (Table 2).

The patient's laboratory results showed hyperthyroidism, which usually occurs in Graves' disease but not in Hashimoto. The diagnosis planning for the patient at the time was Thyroid Biopsy and anti-TPO antibodies (now known as anti-thyroid microsomal antibody). Diagnosis of Hashimoto will be made if lymphocytic infiltration in a lymphoid colloid is observed, and Graves' disease if the epithelial cells no longer surround follicles of the colloid, the follicles disappear and become depleted. ${ }^{4}$ Anti TPO antibodies test was elevated, consistent with the hyperthyroid phase of Hashimoto's disease. The patient got tyrosol and propanolol leading to a state of euthyroid on November $23^{\text {rd }}$.

Anatomical pathology results showed a firm,

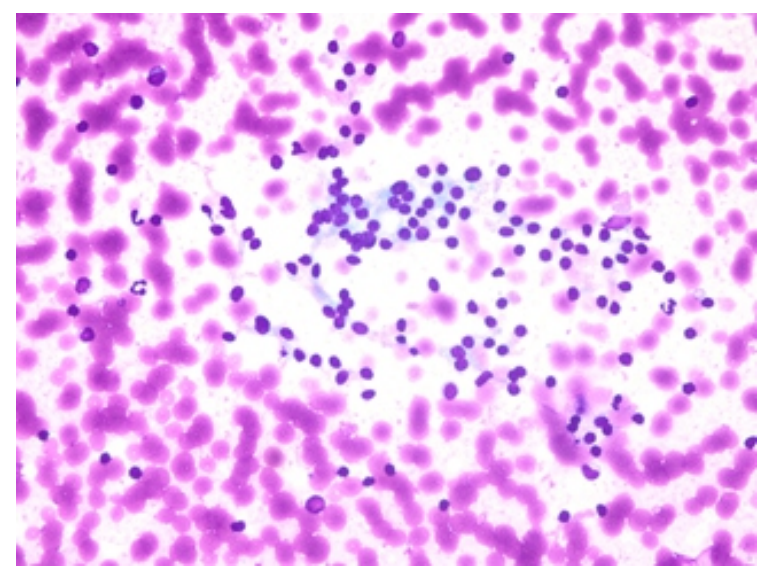

Figure 2. Patient's $F N A B$ showed infiltration of lymphocytes in follicles fixated, and rubbery nodule on the left thyroid, with a size of $4 \times 3 \times 1 \mathrm{~cm}$, and moved while swallowing. As seen in Figure 2, microscopic examination showed cells with groups of epithelial cells in the follicle with a round nucleus, fine monotonous chromatin, and fire-flare appearance. There were lymphocytic cells which spread throughout the follicles and large multinucleated cell with no signs of malignancy. Thus, the conclusion was lymphocytic thyroiditis (Hashimoto's Thyroiditis).

\section{DISCUSSION}

The name Hashimoto's thyroiditis is derived from the 1912 pathology report by Hashimoto describing patients with goiter and intense lymphocytic infiltration of the thyroid as "Struma lymphomatosis". ${ }^{1}$ Hashimoto reported four patients with diffuse goiter and described the four histologic characteristics as follows: diffuse lymphocytic infiltration, formation of lymphoid follicles, destruction of epithelial cells, and proliferation of fibrous tissue. The term Hashimoto disease or Hashimoto thyroiditis is sometimes used to only refer to goitrous thyroiditis. However, it is usually used in a general definition, a synonym of chronic thyroiditis or autoimmune thyroiditis, including atrophic and non-goitrous thyroiditis. ${ }^{2}$

Serum Thyroid-Stimulating Hormone (TSH) levels is a sensitive test of thyroid function; TSH levels are invariably elevated in hypothyroidism due to Hashimoto thyroiditis or another cause. Free T4 levels are needed to correctly evaluate the TSH levels in some clinical settings. Low total T4 or free T4 levels in the presence of an elevated TSH level further

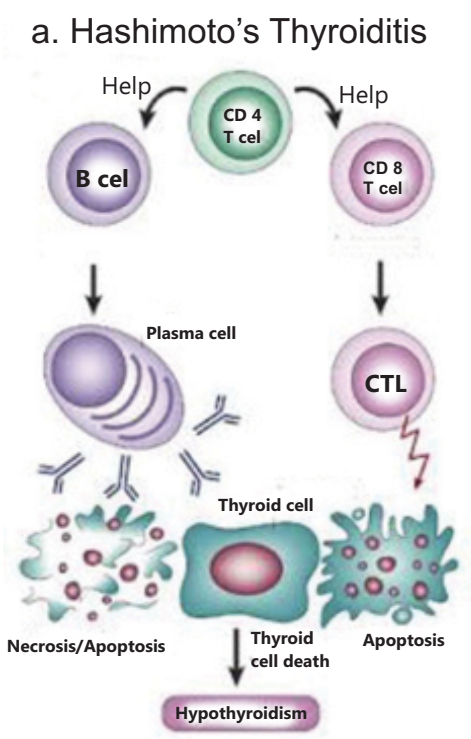

b. Graves disease

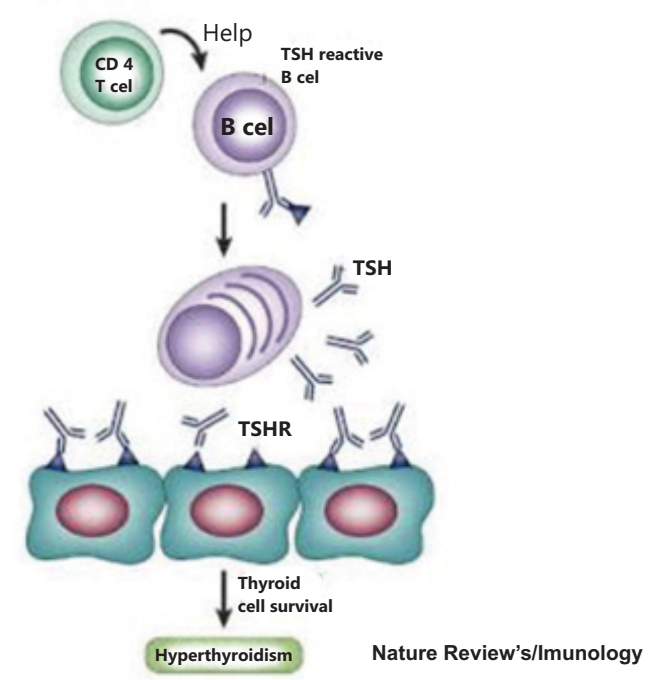

Figure 3. Pathological features of Hashimoto and Graves' thyroiditis ${ }^{8}$ 
confirms the diagnosis of primary hypothyroidism. ${ }^{5}$ This patient had increased free T4 and low TSH levels, indicating primary hyperthyroidism.

While hypothyroidism is characterized by thyroid functional abnormality, the early inflammatory process during the course may involve adequate apoptosis to cause follicular disruption and thyroid hormone release, causing transient hyperthyroidism referred to as Hashitoxicosis. ${ }^{6}$ The general course of Hashimoto's thyroiditis is the gradual loss of thyroid function.

Whenever a patient presents with thyrotoxicosis, common presumed etiologies are Graves' disease and toxic goiters. However, destructive/ inflammatory conditions may also exist, which may damage the thyroid gland, and cause leakage of hormones into the blood leading to thyrotoxicosis. A frequently overlooked cause of destructive thyroiditis is Hashitoxicosis, a term for a transient hyperthyroid phase in chronic autoimmune thyroiditis. In other words, Hashitoxicosis is transient thyrotoxicosis caused by destructive inflammation associated with damaged thyroid follicles by Hashimoto's thyroiditis resulting in excess release of thyroid hormone. Subjects with this disorder are likely to show delayed or even developed hypothyroidism. Hence, Hashitoxicosis seems to directly result from an over-activation of the immune system, simultaneously resulting in clinical features of thyrotoxicosis with pathological features of autoimmune thyroiditis.'

The two extreme forms of the disorder are goitrous autoimmune thyroiditis and atrophic autoimmune thyroiditis, with lymphocytic infiltration as the common pathologic feature and high serum concentrations of antibodies to thyroid peroxidase (TPO) and thyroglobulin ( $\mathrm{Tg}$ ) as the common serological feature. Due to the pathogenic and pathologic similarities, the term Hashimoto's thyroiditis is used for all types of chronic autoimmune (lymphocytic) thyroiditis. ${ }^{8}$ This patient showed an increased anti-TPO level of $306 \mathrm{IU} / \mathrm{mL}$, indicating autoimmune thyroiditis. Elevated TPO antibody level represents risk for many types of thyroid dysfunction and is a general marker of thyroid autoimmunity; a remarkably elevated TPO antibody level is more specific for Hashimoto thyroiditis. ${ }^{9}$ During Hashimoto's thyroiditis, self-reactive $C D 4^{+} T$ lymphocytes recruit $B$ cells and CD8 + cells into the thyroid. Disease progression leads to the death of thyroid cells and hypothyroidism. Both autoantibodies and thyroid-specific cytotoxic T lymphocytes (CTLs) have been presumed to be responsible for the depletion of autoimmune thyrocytes. In Graves' disease, activated $\mathrm{CD}^{+}{ }^{+} \mathrm{T}$ cells induce $\mathrm{B}$ cells to secrete Thyroid-Stimulating Immunoglobulins (TSI) against the Thyroid-Stimulating Hormone Receptor (TSHR), resulting in uncontrolled thyroid hormone production and hyperthyroidism (Figure 3). ${ }^{1,8}$

Almost all patients with Hashimoto's thyroiditis showed high serum concentrations of antibodies to Thyroglobulin (Tg) and Thyroid Peroxidase (TPO). The lower concentration of those antibodies are also found in patients with other thyroid disease such as Graves' disease and in many subjects with no clinical or biomedical features of thyroid disease but suspected with mild thyroiditis (Table 3). Some of the antibodies can pass through the placenta. ${ }^{9}$

Hashimoto's thyroiditis is a histological diagnosis; therefore, fine-needle aspiration biopsy must be performed to exclude malignancy or thyroid lymphoma. Hyperthyroidism is usually associated with Graves' disease, where the histology will show prominent infoldings of hyperplastic follicular epithelium due to the predominant action of Thyroid-Stimulating Immune globulins (TSIs) over that of thyroid growth immune globulins (TGIs). ${ }^{10}$ Meanwhile, lymphocytic cells spread through the follicles were found in this patient, indicating Hashimoto's thyroiditis.

Figure 4 shows the various extra-thyroidal manifestation of Graves' disease. Studies by Frochlich et al. showed that anti-TSHR antibodies affected eye and skin area of Graves' disease with unknown mechanism. Meanwhile, the effects of

Table 3. Estimated prevalence of anti-thyroid antibodies (in \%) ${ }^{1}$

\begin{tabular}{lccc}
\hline \multicolumn{1}{c}{ Group } & Anti-TSHR Ab & Anti - Tg Ab & Anti-TPO $\mathbf{A b}$ \\
\hline General population & 0 & 5 to 20 & 8 to 27 \\
Graves' disease & 80 to 95 & 20 to 70 & 50 to 80 \\
Autoimmune thyroiditis & 10 to 20 & 80 to 90 & 90 to 100 \\
Relative of patients with autoimmune thyroiditis & 0 & 30 to 50 & 30 to 50 \\
Type 1 diabetes & 0 & 30 to 40 & 30 to 40 \\
Pregnant female & 0 & About 14 & About 14 \\
\hline
\end{tabular}




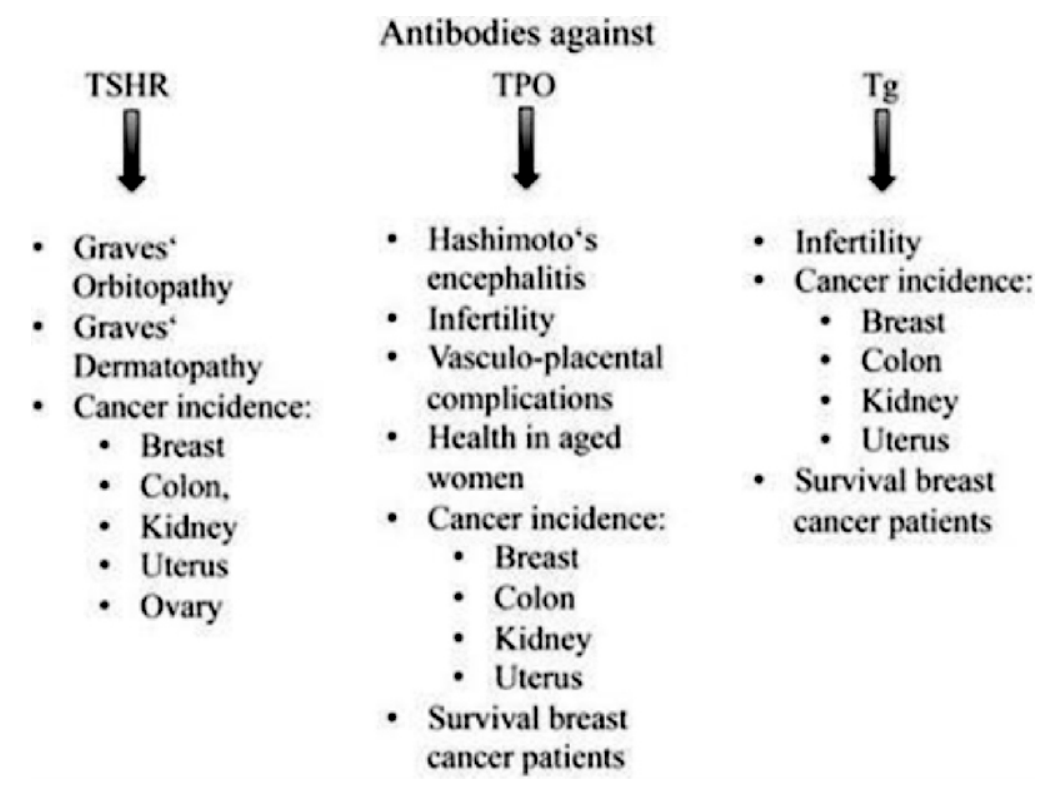

Figure 4. Overview of extra-thyroidal effects of anti-thyroid antibodies ${ }^{11}$

anti-TPO antibodies are greatly various with the central nervous system, female reproductive organs, and female health as the targets of action. The underlying mechanisms are unknown, Anti-Tg antibodies are frequently measured together with anti-TPO antibodies levels, but independent effects have been identified so far. ${ }^{11}$

The patient had hypochromic microcytic anemia that can commonly occur in thyroid disease. Thyroid hormones play a crucial role in hematopoiesis, especially erythropoiesis. They give a direct stimulating effect on the proliferation of erythrocyte precursors and but promote erythropoiesis by increasing erythropoietin gene expression and erythropoietin production in the kidneys. The mechanism of developing anemia in hyperthyroidism is less clear, bone marrow erythroid hyperplasia and elevated levels of erythropoietin are usually detected. Erythrocytosis is a rare phenomenon of erythrocyte morphology, probably due to concomitant iron, vitamin $\mathrm{B} 12$, or folate deficiency. ${ }^{12}$ Altered iron metabolism, hemolysis, and oxidative stress leading to enhanced osmotic fragility of erythrocytes and lipid peroxidation subsequently resulting in shortened erythrocytes survival were suggested as the potential causes of anemia in thyrotoxicosis. Anemia, especially the iron-deficient anemia, may adversely affect the status of thyroid hormones. Iron is vital for the activity of thyroid peroxidase, a crucial iron-containing enzyme for the first step of thyroid hormone synthesis. ${ }^{13}$

Microcytic anemia has been more associated with hyperthyroidism than other thyroid function states. A common phenomenon in hyperthyroid patients, lower MCV, was found in this patient. A high incidence of microcytosis among patients with hyperthyroidism was found, regardless of the hemoglobin status. ${ }^{12}$

Low potassium levels are common in hyperthyroid states. One of the side effects of Graves' disease or thyrotoxicosis is Thyrotoxic Periodic Paralysis (TPP) that has been assumed to be related to increasing $\mathrm{Na}+-\mathrm{K}+$ ATPase activity stimulated by thyroid activity and/or hyperadrenergic activity. This hypothesis cannot clearly explain how hypokalemia occurs during acute attacks or the associated paradoxical depolarization of the resting membrane potential. This patient had hypokalemia but no muscle paralysis was found. Hypokalemia can result from renal or gastrointestinal loss of $\mathrm{K}+$ or $\mathrm{K}+$ shift of into cells induced by acid-base disturbances or endogenous hormones. $^{14}$

Due to an increase of anti-TPO and FT4 levels, a decrease of TSH and lymphocytic thyroiditis on $F N A B$, this patient was diagnosed with a hyperthyroid phase of Hashimoto thyroiditis.

\section{CONCLUSION}

Thyroid function tests and thyroid antibody tests must be monitored to distinguish between the hyperthyroid or hypothyroid phase of Hashimoto thyroiditis.

\section{REFERENCES}

1. Davies, TF. Pathogenesis of Hashimoto's thyroiditis (chronic autoimmune thyroiditis. UpToDate [Internet]. 
2018 [cited 2018 May 12] Available from: https://www.uptodate.com/contents/pathogenesisof-hashimotos-thyroiditis-chronic-autoimmunethyroiditis.

2. Amino, Nobuyuki, John H. Lazarus, Leslie J. De Groot. Chronic (Hashimoto's) thyroiditis. Part 7 thyroid. Endocrinology: Adult and pediatric. Philadelphia, Saunders, 2016; $1515-1527$.

3. Saratziotis, A, Konstatinos Karakousis, Kelly Tzika, Katerina GO, Panagiotis JV. Hashimoto's and Kikuchi's disease: Presentation of a case and a review of the literature. Case Rep Otolaryngol [Internet]. 2012. [cited on May $12^{\text {th }}$ 2018]. Available from: https://www.ncbi.nlm.nih.gov/pubmed/23227401

4. http://medcell.med.yale.edu/histology/ endocrine_sytems_lab /graves_disease.php2018 April 14

5. Lee, SL. Hashimoto Thyroiditis. Medscape [Internet]. 2018. [cited on May $2^{\text {nd }}, 2018$ ] Available from https://emedicine.medscape.com/article/ 120937-overview

6. Fatourechi V, McConahey WM, Woolner LB. Hyperthyroidism associated with histologic Hashimoto's thyroiditis. Mayo Clin Proc [Internet]. 1971. [cited on May $15^{\text {th }}, 2018 ; 46: 687$. Available from: https://www.ncbi.nlm.nih.gov/pubmed/5171000

7. Unnikrishnan AG. Hashitoxicosis: A clinical perspective. Thyroid Res Pract [Internet]. 2013. [cited on May 15 ${ }^{\text {th }}$, 2018; 10(4): 5-6. Available from: http://www.thetrp.net/article. asp?issn =09730354; year $=2013$; volume $=10$; issue $=4$; page $=5$; epage =6; aulast=Unnikrishnan.

8. Stassi G, DeMaria R. Autoimmune thyroid disease: New models of cell death in autoimmunity. Nat Rev
Immunol 2 [Internet]. 2002. [cited on May 15th, 2018; 2: 195-204. Available from: https://www.nature. com/articles/nri750

9. Sweeney LB, Stewart C, Gaitonde DY. Thyroiditis: An integrated approach. Am Fam Physician [Internet]. 2014 [cited on May 17 ${ }^{\text {th }} 2018$ ]; 90 (6): 389-396. Available from https://www.ncbi.nlm.nih. gov/pubmed/25251231

10. University of Utah. Endocrine pathology. Thyroid, Hashimoto's thyroiditis, low power microscope. The internet pathology laboratory for medical education hosted by the University of Utah Eccles Health Sciences Laboratory [Internet]. 2018. [cited on May $\left.15^{\text {th }}, 2018\right]$. Available from https://library.med.utah. edu/WebPath/ENDOHTML/ENDO022.html

11. Frohlich E, Richard W. Thyroid autoimmunity: Role of anti-thyroid antibodies in thyroid and extra-thyroidal diseases. Front. Immunol [Internet]. 2017. [cited on May $15^{\text {th }}, 2018$; 8: 521 Available from https://www.frontiersin.org/articles/10.3389/fimmu.2 017.00521/full

12. Gianoukakis AG, Leigh MJ, Richards P, Christenson PD, Hakimian $A$, et al. Characterization of the anemia associated with Graves' disease. Clin Endocrinol (Oxf). 2009; 70: 781-787.

13. Szczepanek-Parulska E, Hernik A, Ruchala M. Anemia in thyroid disease. Polish archives of internal medicine [Internet]. 2017 [cited on May 20, $2018 ; 127: 5$. Available from: https://www.mp.pl/paim/ issue/article/3985.

14. Lin $\mathrm{SH}$, Huang CL. Mechanism of thyrotoxic periodic paralysis. J Am Soc Nephrol [Internet]. 2012 [cited on May $18^{\text {th }}, 2018 ; 23(6)$ : 985-988. Available from https://www.ncbi.nlm.nih.gov/pmc/articles/PMC3358 $768 /$. 